\title{
Erythema nodosum and pyoderma gangrenosum in 50 patients with Crohn's disease
}

\author{
Hugh J Freeman MD
}

\begin{abstract}
HJ Freeman. Erythema nodosum and pyoderma gangrenosum in 50 patients with Crohn's disease. Can J Gastroenterol 2005; 19(10):603-606.
\end{abstract}

Erythema nodosum and pyoderma gangrenosum may occur in Crohn's disease. In the present evaluation of consecutive patients with Crohn's disease spanning more than two decades, erythema nodosum was seen in 45 patients and pyoderma gangrenosum was seen in seven patients. Forty-one of 566 women (7.2\%) and nine of 449 men (2.0\%) were affected. Of these, 45 (4.4\%) had erythema nodosum and seven $(0.7 \%)$ had pyoderma gangrenosum, including two $(0.2 \%)$ with both dermatological disorders at different times during their clinical courses. Recurrent erythema nodosum was also detected in nine patients (20\%) including eight women, while recurrent pyoderma gangrenosum was seen in two patients $(28.6 \%)$. There was an age-dependent effect on the appearance of erythema nodosum in women, with the highest percentages seen in those younger than 20 years of age. Detection rates for erythema nodosum in women only approached the low mens' rates in Crohn's disease at older than 40 years of age. Most patients with these dermatological disorders had colonic disease with or without ileal involvement as well as complex disease, usually with penetrating complications. The present study documents a sex-based and age-dependent effect on the clinical expression of erythema nodosum in Crohn's disease. This suggests that some components of the inflammatory process in Crohn's disease may be modulated by estrogen-mediated events, particularly in adolescents and young adults.

Key Words: Crohn's disease; Erythema nodosum; Inflammatory bowel disease; Pyoderma gangrenosum; Vienna classification

\section{L'érythème noueux et la pyodermite gangréneuse chez 50 personnes atteintes de la maladie de Crohn}

L'érythème noueux et la pyodermite gangréneuse peuvent se déclarer en cas de maladie de Crohn. Dans la présente évaluation de patients consécutifs atteints de la maladie de Crohn répartie sur plus de deux décennies, un érythème noueux a été constaté chez 45 patients, et une pyodermite gangréneuse, chez sept. Quarante et une des 566 femmes (7,2\%) et neuf des 449 hommes $(2,0 \%)$ étaient touchés. De ce nombre, 45 (4,4\%) souffraient d'érythème noueux, et sept $(0,7 \%)$ de pyodermite gangréneuse, y compris deux patients $(0,2 \%)$ atteints de ces deux troubles dermatologiques à des moments différents de leur évolution clinique. Un érythème noueux récurrent a également été observé chez neuf patients (20\%), dont huit femmes, tandis qu'une pyodermite gangréneuse récurrente l'a été chez deux patients (28,6 \%). L'apparition de l'érythème noueux chez les femmes était reliée à l'âge, les plus forts pourcentages étant constatés chez des femmes de moins de 20 ans. Les taux de dépistage de l'érythème noueux chez les femmes seulement avoisinaient les taux les plus faibles des hommes de plus de 40 ans atteints de la maladie de Crohn. La plupart des patients atteints de ces troubles dermatologiques souffraient d'une maladie colique accompagnée ou non d'une atteinte iléale, complexe, généralement combinée à des complications pénétrantes. La présente étude documente que l'expression clinique de l'érythème noueux en cas de maladie de Crohn dépend du sexe et de l'âge. Ce constat laisse supposer que certains éléments du processus inflammatoire de la maladie de Crohn seraient modulés par des événements assistés par les œestrogènes, notamment chez les adolescentes et les jeunes adultes.
C rohn's disease is a heterogeneous inflammatory disorder that involves different sites along the length of the intestinal tract and may be characterized by a high rate of stricture formation and penetrating disease complications (1-3). Because the clinical patterns are phenotypically variable, recent attention has focused on defining homogenous patient groups with more uniform clinical characteristics, including patient age at diagnosis, sex, disease location and disease behaviour, using a modern schema of classification developed in Vienna (4).

In Crohn's disease, a number of extraintestinal manifestations may occur. Among the most common are dermatological disorders (5-7). Erythema nodosum is an inflammatory process of poorly defined pathogenesis that seems to appear sporadically, usually during the first two years of the intestinal disease, as one or more tender and erythematous subcutaneous nodules, often symmetrically distributed and relatively well circumscribed. These are most often visualized on the extensor surfaces of the legs (ie, pretibial region), but almost any site in the upper and lower extremities may be susceptible. In Crohn's disease, prior studies have estimated this disorder to occur in $2 \%$ to $15 \%(8,9)$. Pyoderma gangrenosum is a chronic, usually ulcerative inflammatory process that may occur on the body at any site, although the lower extremities or areas susceptible to trauma (ie, pathergy near incisions or adjacent to a stoma) are most often affected. The lesion is reported in less than 2\% of patients with Crohn's disease $(8,9)$. Development of either condition is often a relatively abrupt event, although with pyoderma, evolution of lesions may be seen, sometimes beginning with a pustule that progresses rapidly to frank ulceration. For both, recurrent lesions or clusters of lesions may occasionally be seen $(5,10)$. Other distinctive granulomatous or reactive dermatological disorders may occur in Crohn's disease (eg, metastatic Crohn's disease or Sweet's syndrome) but these usually require histological confirmation.

Department of Medicine (Gastoenterology), University of British Columbia, Vancouver, British Columbia

Correspondence: Dr Hugh James Freeman, University of British Columbia Hospital, 2211 Wesbrook Mall, Vancouver, British Columbia

V6T 1W5. Telephone 604-822-7216, fax 604-822-7236, e-mail hugfree@shaw.ca

Received for publication April 11, 2005. Accepted May 31, 2005 


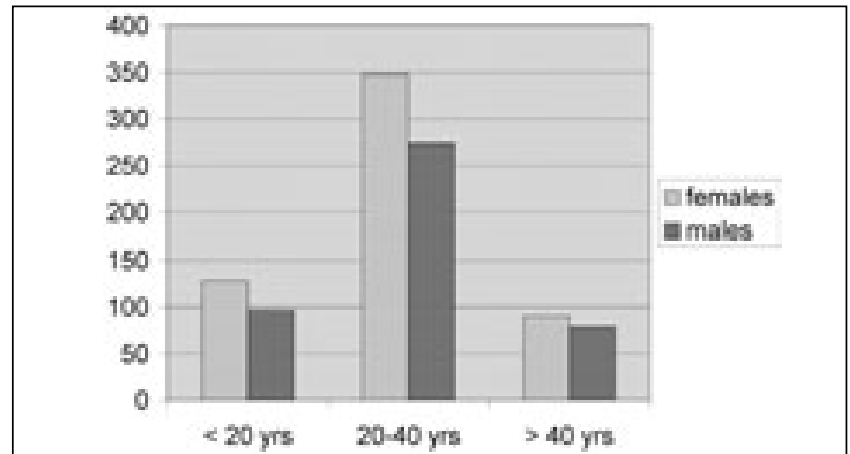

Figure 1) Age distribution of women and men with Crohn's disease $(n=1015$ patients). yrs Years

The present investigation applied a modern classification schema of Crohn's disease (4) to a large, prospectively accumulated database with over a decade of continuous follow-up by a single clinician, to explore the roles of sex and aging on the common dermatological disorders often recorded in Crohn's disease: erythema nodosum and pyoderma gangrenosum. The results suggest that the pathogenetic basis for these dermatological disorders in Crohn's disease, particularly erythema nodosum, is strongly related to female sex, especially during adolescent and young adult years.

\section{METHODS}

\section{Definitions and inclusions}

Patients were derived from a clinical database consisting of 1015 consecutively evaluated patients having a diagnosis of Crohn's disease and directly treated by the investigator over more than two decades. The mean period of patient follow-up was over 10 years (1). Figure 1 shows that this population was predominantly female with over $80 \%$ diagnosed before 40 years of age, similar to a previous report for the initial 877 patients (1). As shown in Table 1, disease was most often detected in the ileocolon with a high rate of complex disease (ie, over 70\%), including stricture formation and penetrating complications. As noted elsewhere (1-3), for all patients in the present evaluation, office and inpatient hospitalization records as well as endoscopic, radiological imaging, surgical and pathology reports were recorded. Statistical analyses were performed using Student's $t$ test or $\chi^{2}$ analysis.

For the patients with either erythema nodosum or pyoderma gangrenosum, a clinical consultation from specialized dermatologists was usually obtained for confirmation of the skin disorder. Most often, this consisted of clinical examination only, although some patients had routine cultures and, sometimes, skin biopsies performed. No other patient with erythema nodosum and/or pyoderma gangrenosum had any other superimposed 'reactive' cutaneous disorder associated with Crohn's disease, including the clinical spectrum of neutrophilic dermatoses sometimes associated with Crohn's disease. Two men in this series had both erythema nodosum and pyoderma gangrenosum at separate times during their clinical courses. In one patient with severe colonic disease diagnosed at 27 years of age, this developed postoperatively in peristomal skin after a partial colonic resection with a residual rectal stump. In one woman in this series with erythema nodosum, diagnosed at 43 years of age with Crohn's disease, superimposed metastatic cutaneous Crohn's disease with granulomatous change was histologically defined in a separate lesion on her posterior thigh.
TABLE 1

Classification of Crohn's disease patients $(n=1015)^{\star}$

\begin{tabular}{lcccc}
\hline & All & $<\mathbf{2 0}$ yrs & $\mathbf{2 0 - 4 0}$ yrs & $>\mathbf{4 0}$ yrs \\
\hline Disease site & & & & \\
Ileum & 23.4 & 18.8 & 25.2 & 23.1 \\
Colon & 29.5 & 19.6 & 28.0 & 47.9 \\
lleocolon & 35.4 & 42.9 & 36.0 & 23.1 \\
UGI tract & 11.7 & 18.8 & 23.1 & 5.9 \\
Disease behaviour & & & & \\
NSNP & 29.9 & 21.9 & 29.2 & 40.5 \\
Strict & 29.8 & 29.2 & 27.0 & 36.7 \\
Penet & 38.4 & 49.0 & 43.4 & 22.8 \\
\hline
\end{tabular}

${ }^{*}$ Based on a modification of the Vienna classification system (4). All numbers are percentages. NSNP Nonstricturing and nonpenetrating; Penet Penetrating; Strict Stricturing; UGI Upper gastrointestinal; yrs Years

\section{Classification method}

Male and female patients were each classified based on a previously published schema developed elsewhere (4), that was previously applied by the author to a single-clinician Crohn's disease database (1). For the present evaluation, however, a modification of the Vienna schema (3) was necessary to create a younger than 20 years of age group; this classification schema does not differentiate specific age groups younger than 40 years of age. Other defining features of the Vienna classification (4) were used, including location of disease defined as the maximal extent of disease or disease at the first resection (ie, L1, ileum, possibly involving cecum; L2, colon; L3, ileocolon; L4, upper gastrointestinal tract regardless of other disease sites) and disease behaviour (eg, B1 nonstricturing and nonpenetrating; B2 stricturing; B3 penetrating). In this classification schema, disease is defined as B3 if, at any time during the course of the disease, intra-abdominal or perianal fistula, perianal ulceration, inflammatory mass and/or abscess have developed, even if a coexisting stricture is present. In contrast to the definition of disease location, the definition of disease behaviour in the Vienna classification has no specific time limit. For the present study, disease behaviour was defined in a cumulative fashion as the most recent patient encounter during the past three years.

\section{RESULTS}

\section{Patient group}

Figure 1 shows the entire population of 1015 Crohn's disease patients evaluated directly by the clinician investigator for more than two decades. As shown for each age group, there was a predominantly female pattern. In the database, there were a total of 50 patients (4.9\%) with erythema nodosum and/or pyoderma gangrenosum. This included 45 patients with erythema nodosum $(4.4 \%)$ and seven patients with pyoderma gangrenosum $(0.7 \%)$. Two patients had both dermatological disorders $(0.2 \%)$. Although not further evaluated here, metastatic cutaneous Crohn's disease with granulomas was recorded in one woman from this population with erythema nodosum. These values for erythema nodosum and pyoderma gangrenosum approximate percentages reported from a similar large study that used a coded database over a 10-year period of evaluation, rather than direct clinician evaluation here for a similar mean period of patient follow-up over 10 years (11). In this patient group, 41 of 566 women (7.2\%) and nine of 449 men $(2.0 \%)$ were affected with either erythema nodosum or pyoderma gangrenosum. The results from this prospectively accumulated database approximate the reported frequencies for these dermatological disorders detailed elsewhere in retrospective surveys (8-10) and a single prospective study (12). 


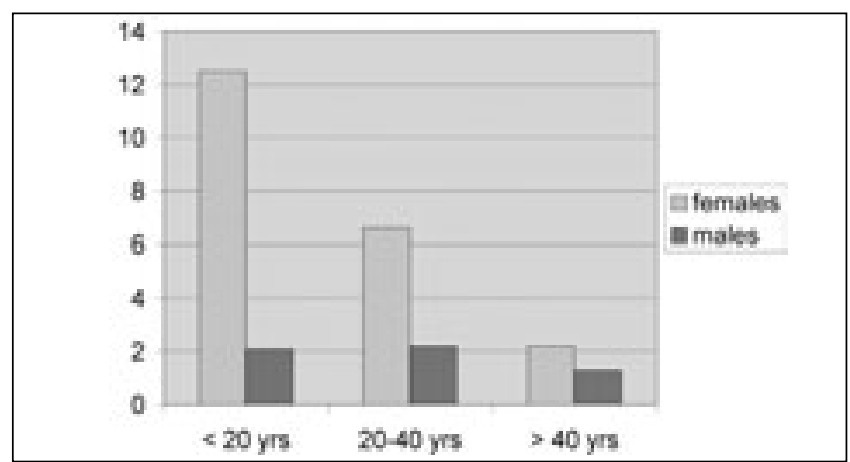

Figure 2) Percentages of women and men at each group with dermatological disorders (erythema nodosum and pyoderma gangrenosum). For women, there was a significant difference between the younger than 20 years of age group, the 20 to 40 years of age group and the older than 40 years of age group $($ all $P<0.05)$. yrs Years

In this population, recurrent erythema nodosum was also detected in nine patients (20\%; eight women and one man, $\mathrm{P}<0.05)$, while recurrent pyoderma gangrenosum was seen in two patients (28.6\%; one woman and one man).

\section{Patient age}

Figure 1 shows patient age at diagnosis. For the entire group of 1015 patients, $846(83.3 \%)$ were diagnosed younger than 40 years of age and $169(16.7 \%)$ were diagnosed older than 40 years of age $(\mathrm{P}<0.05)$. These results from a continuously accumulating patient database are similar to previously published results using this modern Vienna classification for the first 877 patients (1). In addition, using the Vienna schema that was previously modified for age at diagnosis younger than 40 years (3), 224 patients (22.1\%) were diagnosed at younger than 20 years of age, while $622(61.3 \%)$ were diagnosed between 20 and 40 years of age.

Figure 2 shows that for each of the groups with Crohn's disease with these dermatological disorders, a greater percentage of women were affected for each age group at diagnosis (all $\mathrm{P}<0.05)$. There were 18 patients diagnosed at younger than 20 years of age (16 of 128 women and two of 96 men), 29 diagnosed between 20 and 40 years of age ( 23 of 348 women and six of 274 men) and three diagnosed after 40 years of age (two of 90 women and one of 79 men). Indeed, for the group younger than 20 years of age, the youngest women diagnosed with erythema nodosum were 14 years of age or older at the time of diagnosis and the youngest man was 15 years at diagnosis (ie, no patient was diagnosied younger than 14 years of age with either dermatological disorder). In addition, in this younger than 20 years age group, only one woman, diagnosed with Crohn's disease at 14 years of age, had pyoderma gangrenosum.

As shown in Figure 2, for women, but not for men, these dermatological disorders were seen more frequently if the diagnosis of Crohn's disease was established at an earlier age $(\mathrm{P}<0.05)$. This age-related effect was primarily related to detection of erythema nodosum alone $(\mathrm{P}<0.05)$; only one woman in this population group was detected with pyoderma gangrenosum at younger than 20 years of age (see above). All others in this population with pyoderma gangrenosum, specifically, three women and three men, were each diagnosed with Crohn's disease later, between 20 and 40 years of age.

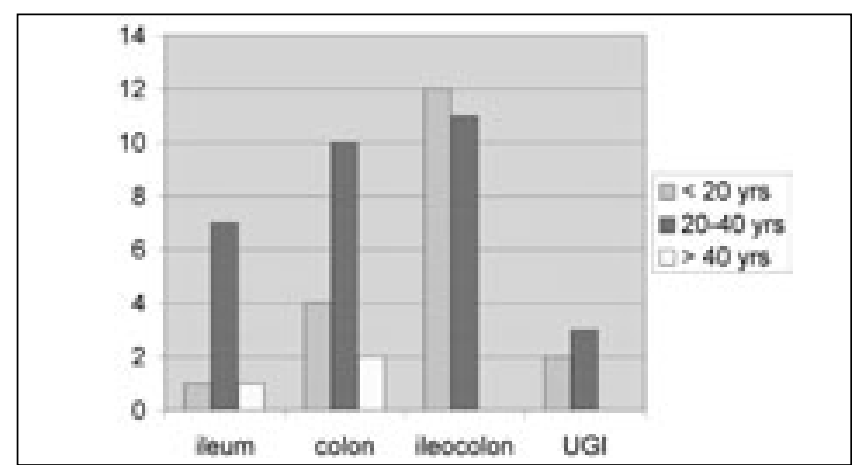

Figure 3) Percentages of dermatological disorders in each group with Crohn's disease in different locations. Most often, the colon was involved with or without ileal disease for all age groups. UGI Upper gastrointestinal; yrs Years

\section{Disease site}

Table 1 shows the percentage of patients in each age group based on disease location as defined by the modern Vienna schema (1), but modified to permit evaluation of patients diagnosed younger than 20 years of age (3). As shown, patients diagnosed younger than 20 years of age had more extensive disease, usually with ileocolonic involvement and disease in the upper gastrointestinal tract $(\mathrm{P}<0.05)$ while patients diagnosed older than 40 years of age more often had disease localized to the colon alone $(\mathrm{P}<0.05)$. Similar findings (data not shown) were observed for both men and women.

Figure 3 shows the percentage of patients with erythema nodosum and/or pyoderma gangrenosum in each age group for each site of disease involvement. Most had colonic involvement either alone or, more often, combined with ileal involvement, consistent with previous reports $(8-10)$. Although there were some that had ileal disease alone, even those classified with upper gastrointestinal tract disease (as per the Vienna schema), most often had ileocolonic disease (ie, all four women). Interestingly, however, a single man in this patient series had erythema nodosum and upper gastrointestinal tract disease alone. He was initially diagnosed with Crohn's disease involving the jejunum and ileum at 15 years of age and has been followed for 18 years. To date, no colonic disease has been detected.

\section{Disease behaviour}

Table 1 shows the percentages of patients in this population classified with different types of disease behaviour. For each of the different age groups, most patients suffered from complex clinical disease with strictures or penetrating complications. Figure 4 shows the percentage of different disease behaviour patterns in each age group with Crohn's disease that were affected by either erythema nodosum or pyoderma gangrenosum. Shown is each form of disease behaviour for each age group. However, the most striking finding was that the majority of patients with one of these two dermatological disorders ultimately developed a penetrating disease complication. This was observed for both of the younger age groups (younger than 20 years of age and 20 to 40 years of age; both, $\mathrm{P}<0.05)$.

In over $70 \%$ of women ( 29 of 41 ), disease behaviour could be classified as complex with either strictures (nine patients) or penetrating disease complications (20 patients). Interestingly, in 


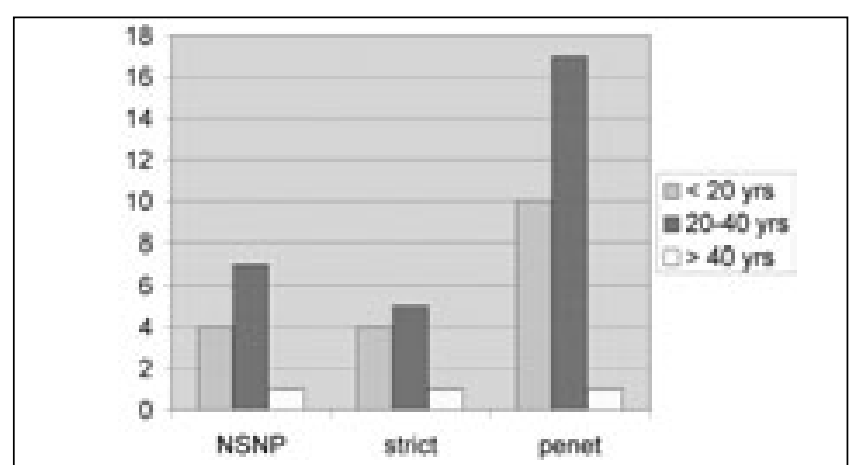

Figure 4) Percentages of dermatological disorders in each group with Crohn's disease based on disease behaviour. Complex behaviour types were common, particularly penetrating disease complications, in patients younger than 40 years of age $(P<0.05)$. NSNP Nonstricturing and nonpenetrating; Penet Penetrating; Strict Stricturing; yrs Years

men, all had complex disease, and all eight of those younger than 40 years of age had penetrating disease complications.

\section{DISCUSSION}

Dermatological disorders are among the most commonly detected extraintestinal manifestations in Crohn's disease (5-10). In the present population-based evaluation using prospectively accumulated data in Crohn's disease, erythema nodosum and pyoderma gangrenosum were seen in $4.9 \%$ and $0.7 \%$ of patients, respectively. These results in consecutively evaluated patients with Crohn's disease accumulated for more than two decades in a focused clinical practice and using a modern method of classification approximate historical results described in previous large, retrospective surveys (8-10), the only other large prospective study (12) and a large population-based study that employed disease-coded source materials for database construction (11).

The most striking feature in this Crohn's disease population was the sex-based appearance of erythema nodosum. Here, 45 of the 50 patients ( $90 \%$ ) had erythema nodosum, and of those, 37 (greater than $80 \%$ ) were women. Moreover, recurrent episodes of erythema nodosum were almost exclusively a female sexbased phenomenon. A predominance of women with erythema nodosum in Crohn's disease has been previously noted (11). Here, however, the most commonly affected group were women diagnosed younger than 20 years of age, and specifically, between 14 and 20 years of age. Specific age-dependent effects on the appearance of this dermatological disorder were also observed with the next most frequent group involved, ie, women diagnosed between 20 and 40 years of age. Only women older than 40 years of age approached the low male sex-based percentage rates detected in this population. Even though erythema nodosum has been recorded in infants and young children, it is usually associated with other causes, such as sarcoidosis or infectious agents (eg, streptococcus, yersinia and mycobacteria) $(13,14)$, less often Crohn's disease. These sex-based effects on the time of clinical expression of this dermatological disorder in Crohn's disease represent a new observation. Given its appearance mainly during adolescence and in young adults, it is tempting to hypothesize that this dermatological inflammatory process in Crohn's disease may possibly represent a hormonally mediated (ie, estrogen) effect on the phenotypic clinical expression of Crohn's disease.
Interestingly, estrogen-mediated effects on adipose tissue cytokines have also been observed by others $(15,16)$ and modulatory effects of estrogen on cytokines involved in murine models of colitis have been described (17). Further investigative studies to explore the role of sex steroids, particularly female hormones, including exogenous sources (eg, contraceptive medication) on the clinical expression of Crohn's disease and mechanisms involved in the inflammatory process per se are needed.

The present study also explored the relationship of these dermatological disorders to Crohn's disease site and disease behaviour. By employing the Vienna classification here for the first time with these disorders, this evaluation confirmed descriptions in earlier reports showing colonic involvement with or without ileal disease (8-10). In addition, in one patient, erythema nodosum developed in the presence of extensive small intestinal disease but without detectable colonic disease, emphasizing that these dermatological disorders cannot be relied upon solely as a phenotypic clinical marker of underlying colonic disease. Interestingly, most patients developed complex disease; particularly, perforating complications. This finding suggests that these dermatological disorders, particularly erythema nodosum, known to usually occur in the early clinical course of the disease, may eventually serve as a useful clinical predictor of later, more complex, Crohn's disease, particularly perforating disease complications.

\section{REFERENCES}

1. Freeman HJ. Application of the Vienna classification for Crohn's disease to a single clinician database of 877 patients. Can J Gastroenterol 2001;15:89-93.

2. Freeman HJ. Natural history and clinical behavior of Crohn's disease over two decades. J Clin Gastroenterol 2003;37:216-9.

3. Freeman HJ. Comparison of longstanding pediatric-onset to adult-onset Crohn's disease. J Pediatr Gastroenterol Nutr 2004;39:183-6.

4. Gasche C, Scholmerich J, Brynskov J, et al. A simple classification of Crohn's disease: Report of a working party for the World Congress of Gastroenterology, Vienna 1998. Inflamm Bowel Dis 2000;6:8-15.

5. McCord ML, Hall RP. Cutaneous manifestations of inflammatory bowe disease. In: Targan SR, Shanahan F, eds. Inflammatory Bowel Disease: From Bench to Bedside. Baltimore: Williams and Wilkins, 1994;682-94

6. Levine JB. Extraintestinal manifestations of inflammatory bowel disease. In: Kirsner JB, ed. Inflammatory Bowel Disease. 5th edn. Philadelphia: WB Saunders, 2000:397-409.

7. Sidorov JJ. Extraintestinal manifestations of inflammatory bowel disease. In: Freeman HJ, ed. Inflammatory Bowel Disease, Vol 2. Boca Raton: CRC Press, 1989:51-74.

8. Greenstein AJ, Janowitz HD, Sachar DB. The extra-intestinal complications of Crohn's disease and ulcerative colitis: A study of 700 patients. Medicine 1976;55:401-12

9. Mir-Madjlessi SH, Taylor JS, Farmer RG. Clinical course and evolution of erythema nodosum and pyoderma gangrenosum in chronic ulcerative colitis: A study of 42 patients. Am J Gastroenterol 1985;80:615-20.

10. Jacobs WH. Erythema nodosum in inflammatory diseases of the bowel. Gastroenterology 1959;37:286-94

11. Bernstein CN, Blanchard JF, Rawsthorne P, Yu N. The prevalence of extraintestinal diseases in inflammatory bowel disease: A population-based study. Am J Gastroenterol 2001;96:1116-22.

12. Veloso FT, Carvalho J, Magro F. Immune-related systemic manifestations of inflammatory bowel disease. A prospective study of 792 patients. J Clin Gastroenterol 1996;23:29-34.

13. Labbe L, Perel Y, Maleville J, Taieb A. Erythema nodosum in children: A study of 27 patients. Pediatr Dermatol 1996;13:447-50.

14. Kakourou T, Drosatou P, Psychou F, Aroni K, Nicolaidou P. Erythema nodosum in children: A prospective study. J Am Acad Dermatol 2001;44:17-21.

15. Bruun JM, Nielsen CB, Pedersen SB, Flyvbjerg A, Richelsen B. Estrogen reduces pro-inflammatory cytokines in rodent adipose tissue: Studies in vivo and in vitro. Horm Metab Res 2003;35:142-6.

16. Deb S, Amin S, Imir AG, et al. Estrogen regulates expression of tumor necrosis factor receptors in breast tissue adipose fibroblasts. J Clin Endocrinol Metab 2004;89:4018-24

17. Verdu EF, Deng Y, Bercik P, Collins SM. Modulatory effects of estrogen in two murine models of experimental colitis. Am J Physiol Gastrointest Liver Physiol 2002;283:G27-36. 


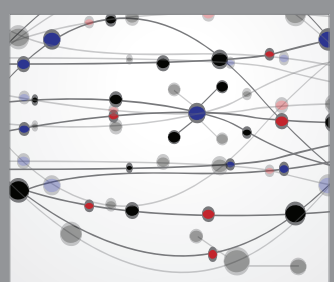

The Scientific World Journal
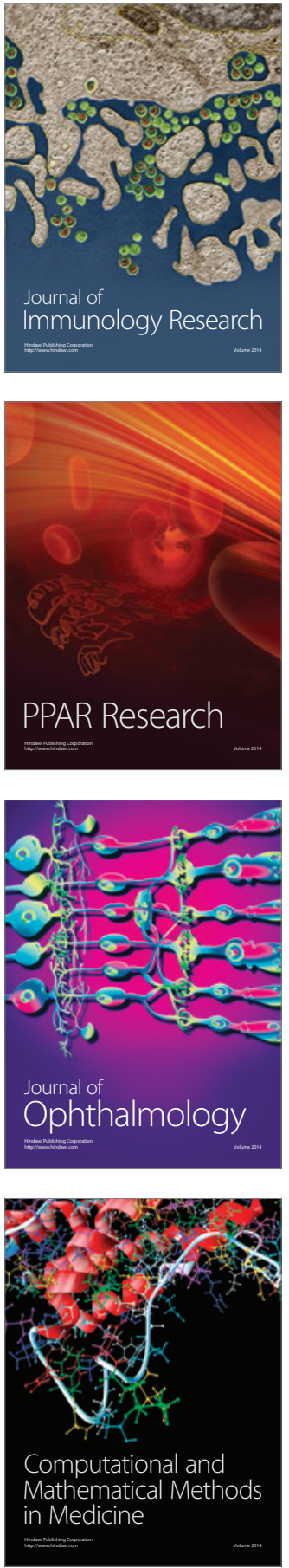

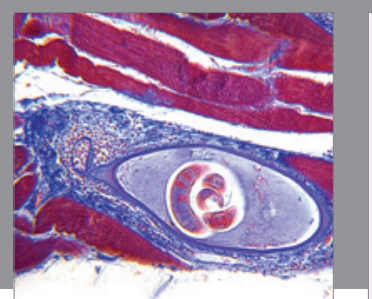

Gastroenterology Research and Practice

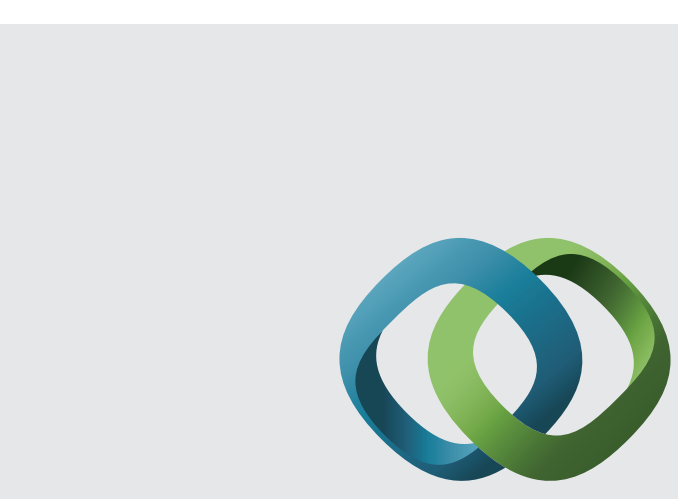

\section{Hindawi}

Submit your manuscripts at

http://www.hindawi.com
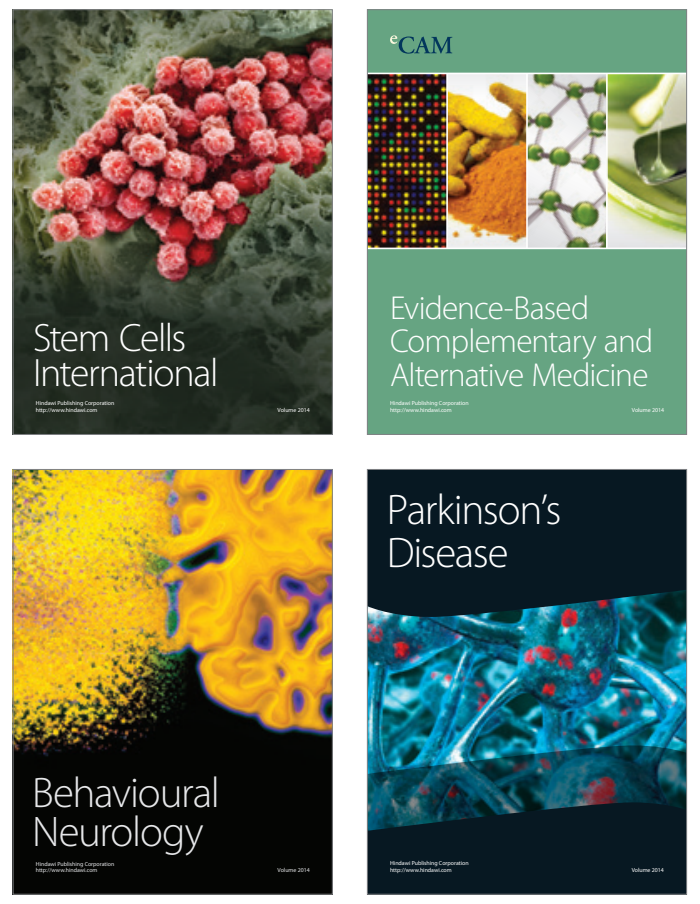
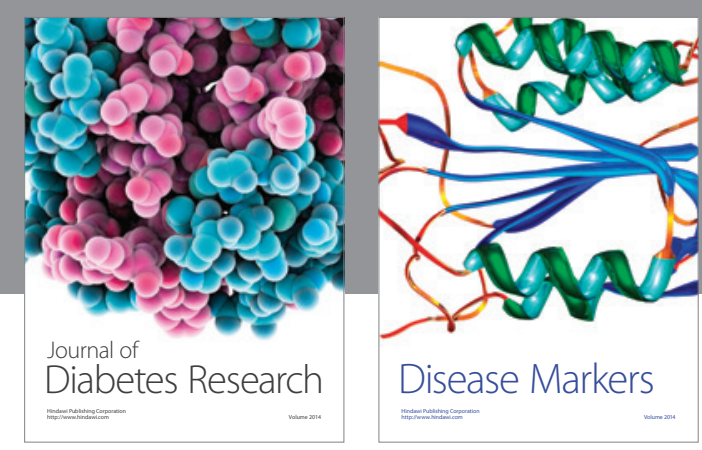

Disease Markers
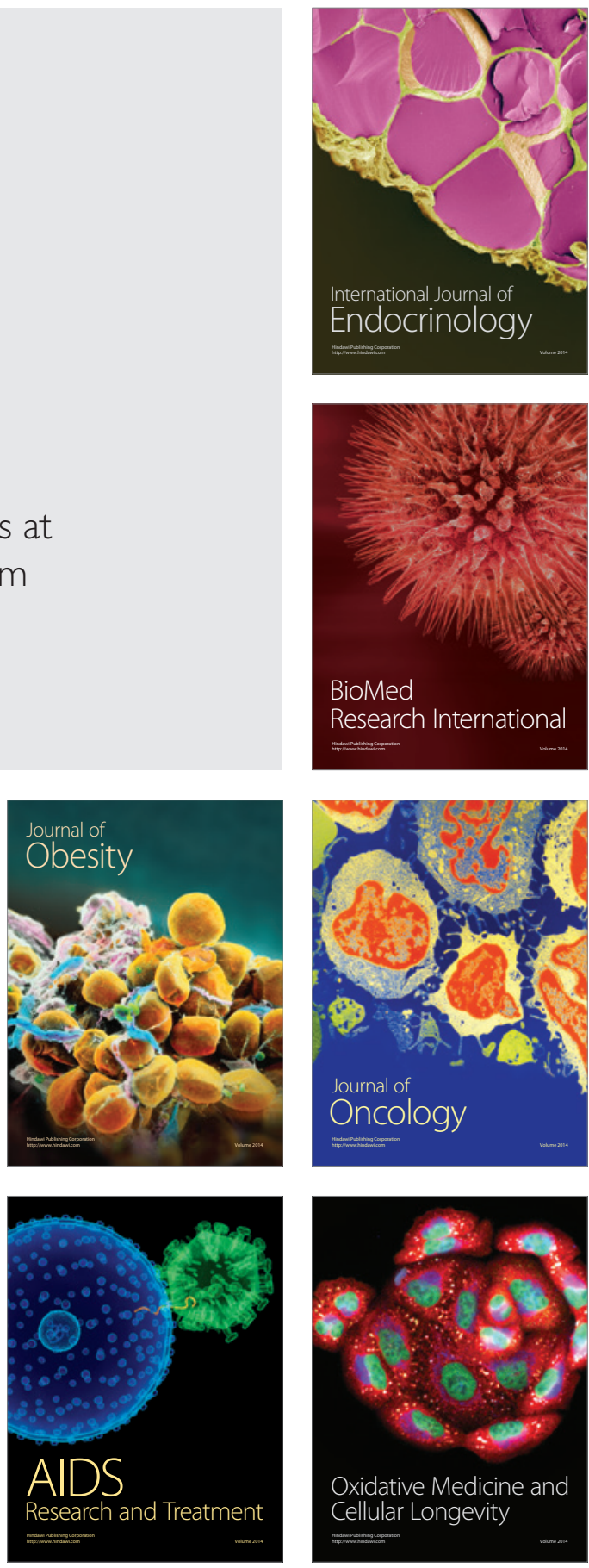